\title{
The Market as a Decision-Making Mechanism in a Democracy
}

\author{
Panagiotis Evangelopoulos ${ }^{1}$ \\ ${ }^{1}$ Department of Economics, University of Peloponnese, Arcadia, Tripolis, Greece \\ Correspondence: Panagiotis Evangelopoulos, Department of Economics, University of Peloponnese, Arcadia, \\ Tripolis, 22100, Greece. Tel: 30-2710-230-070. E-mail: panevans@uop.gr
}

Received: July 22, 2015

Accepted: September 17, 2015

Online Published: October 25, 2015

doi:10.5539/ijef.v7n11p260

URL: http://dx.doi.org/10.5539/ijef.v7n11p260

\begin{abstract}
In my paper I attempt to show that the market is an effective decision-making mechanism in a modern democracy. On the other hand, in a contemporary democratic society, the state must have a limited role, only on the formation of the collective choice through the majority rule. The majority rule is required for the proper functioning of social organization, with the voting mechanism within a framework of strict limitations imposed by individuals with high-level constitutional backing for the effective protection of the individual rights.
\end{abstract}

Keywords: market mechanism, majority rule, collective choice, voting paradox, individual rights

\section{Introduction}

My argument in this paper is that we perform the greatest service to the public interest by having the government reduce state intervention. Conversely, reduction of the presence of the state in a modern democratic community leaves space for the greater part of individual decision-making to take place within the market. In my paper I attempt to show that the market is an effective decision-making mechanism appropriate for furtherance of the public interest (Note 1).

The market is an effective and consistent instrument for individual decision making because the decisions that are implemented within it do not impinge upon the rights of other individuals and are not imposed unilaterally. The reason for this is that no decision is taken within the market unless it is mutually beneficial. Decisions taken within the market require neither general acceptance nor a dictatorship of the few or of an individual with unilateral and coercive consequences. No decision can be taken if there is disagreement from some person or some group among the contracting partners, given that they always have the right to withhold their consent, to decline to participate and to abstain from the undesired transaction. The market thus leaves all responsibility with the individual for his actions and their consequences.

\section{Analysis of the Collective Choice}

At this point however, in a democratically organized community, the basic question arises of the decision, which must necessarily be collective, for securing of the common good. It is at precisely this point that Kenneth Arrow's (Note 2), General Possibility Theorem (Note 3) of the economy of well-being (Note 4) is pertinent. It asserts in general that there is no mechanism capable of eliciting a collective decision from individual values without violating them. Arrow's theorem is as much opposed to the mechanism of the market as it is to the mechanism of voting, insofar as it is consistent in protecting individual values when by means of such mechanisms we reach collective decisions and choices. The critique articulated in Arrow's theorem focuses above all on the voting mechanism. It is for this reason that it has been designated the Voting Paradox. The Voting Paradox leads to the general proposition that the rule of the majority does not yield a consistent rational collective decision that can avoid violating individual values and preferences. The significance of this theory can be seen in its ultimate findings, namely that since the rule of the majority is inadequate, it is not possible for a maximisation of social well-being to be derived from it that can serve as a basis for optimal collective choice grounded on individual values.

The implications of Arrow's argument on the Voting Paradox are a loss of status for the rule of the majority vote as a mechanism for taking collective decisions but also for autonomous decisions taken via the market mechanism. We propose to demonstrate that Arrow's argument is led to this outcome because on the one hand he fails to situate the rule of the majority within its proper dynamic, on the other because he draws a distinction between the market mechanism and individual choice, implying specifically the independent nature of 
transactions carried out by individuals between themselves, without social or other collective involvement and without agreed preliminary ordering of their private preferences.

Arrow sets himself the task of finding a way to move from individual preferences to a collective decision or choice. What is thus required is elaboration of a social well-being function that is capable of satisfying the conditions (Note 5) set by Arrow so as to be susceptible of maximization, i.e. of being enacted by society as a whole. The ideal for Arrow is the rational social collective decision. This logic indeed has validity to it but it is entirely unrelated to what the market does, because the market as a decision-making mechanism does not presuppose a social well-being function where the community decides once and for all, for all its members. It presupposes many individual well-being functions, with each individual deciding for himself and enacting his own maximization.

The conclusion is thus that Arrow's theorem is not capable of constructing a social well-being function and not that the market as a decision-making mechanism is not consistent. Indeed the fact that it is impossible to construct a social well-being function means that it is superfluous to go looking for that potential which society as a whole is to maximize, but that it should be left to each individual separately to maximize it so that we arrive at a collective outcome that is the product of a multiplicity of autonomous and mutually independent maximizations. This is precisely the mode of operation of the market, securing effective social collaboration and a consistent collective outcome. It is therefore essential that we acquire a detailed understanding of the distinction between the social well-being function, which does not exist, so that its maximization in society as a whole is an impossibility, and the decision-making mechanism of the market, which as such is unaffected by Arrow's conditions, which are however satisfied by each individual in the community separately, each in his own autonomous and independent maximization.

\section{Analysis of the Majority Rule}

We shall now examine the rule of the majority, because this is more closely interwoven with Arrow's theorem and with social choice. The rule of the majority is not compatible with the market. It is an alternative decision-making mechanism to the market in modern democracies. In essence the rule of the majority is the action mechanism bestowing political power on a broader coalition of individuals so that they may reach a collective decision on important issues of social management, in an organized and democratic manner, constitutionally prearranged and acceptable to all, but at the responsibility of the community as a whole, and with consequences for it, given the existence of an organized minority which disagrees with, and reacts against, the choices of the majority. The rule of the majority in this sense is a mild dictatorship, based on consensus among a grouping of individuals, numerically larger, but who nevertheless always impose their decisions in the face of resistance from a minority. Despite this disadvantage, however, of being, and continuing to be, a kind of dictatorship, it has the advantage of functionality and of a potential for change over time in the coalitions and the composition of the individuals constituting it.

Thus in practice, in contemporary forms of social organization where democracy prevails with the co-existence of state and the market, the rule of the majority solves the problem of inertia-that is to say of non-taking of decisions on account of intense disagreement-on the one hand, while at the same time avoiding dictatorship, that is to say imposition of the will of one individual or of a well organized, compact, and intransigent minority, over all the others. At the same time the democratic alternation of coalitions in the position of majority places narrow limits on this quasi dictatorial character of the majority rule, rendering it rigorously accountable to the minority in such a way that a collective decision by the majority is experienced for the most part as tolerable and not so much as an imposition, by minorities and individuals. Finally the democratic functioning of the law of the majority presupposes a very broad majority defending and protecting the inviolability of general principles, values and individual rights, which is the quasi unanimity of all individuals, and this is summarized and codified in the Constitution, which is the constitutive document for the functioning of democracy within the framework of which the voting mechanism and the resultant rule of the majority yields its results. It is for this reason that, from a technical viewpoint, constitutions must be constructed in such a way as to be simple, straightforward and comprehensive because this is conducive to consensus, not leaving operational margins for the rule of the majority to produce improper outcomes contravening individual values and preferences.

\section{Analysis of the Market Mechanism}

In the light of all this and in contrast to the disadvantages presented by the rule of the majority, the market appears the more open and participatory process for decision making. A significant part of the overall volume of decision-making in a modern democracy is indeed effectuated through it and underwritten by it. The market also provides a reliable channel for decision making in simple everyday processes where the rule of the majority as 
embodied in the tasks of government would not only come into conflict with individual preferences but would also be positively ineffective owing to the high transaction cost of implementing it in each individual case. (Note 6) On the other hand the voting mechanism and the rule of the majority is the touchstone for decision making in a democracy, laying the foundations for democratically-controlled state intervention. The possibility-in the time made available by democracy-of changing the composition of majorities essentially transforms the decisions reached through the voting mechanism into provisional endeavours always revocable by the new majority of the people taking part in the next vote. This moderates the dictatorial character of the rule of the majority, rendering it tolerable in its social application.

Thus in a democratically organized society the market constitutes the principal decision-making mechanism that is consistent with individual values. The decisions that are taken by means of the market mechanism are a multiplicity of separate individual decisions which however lead inescapably to an indisputably collective outcome. This collective outcome of the market is supplemented by collective decisions effectuated by the society through the voting mechanism. To the degree, therefore, that we minimize state intervention we limit the incompatibility of collective decisions with individual values as well as the possibility of mistakes that can be made by the government at the expense of individuals, not to mention arbitrary acts that may be committed by the majority at the expense of the minority or of individuals. In either case democracy benefits when it limits the purview of collective decisions taken through the voting mechanism and when it leaves more leeway for the market mechanism to lead the community to a collective outcome based on individual decisions and values.

\section{Conclusion}

In a democratic society the state must have a limited role, leaving the maximum possible decision-making space to the market. As I have attempted to demonstrate in this paper, on the basis of the principles of the positive approach to economics, the state must be treated as a mechanism for community action subject to rational restraints imposed by individuals in constitutive agreement between themselves so that their collaboration may take place in an organized manner, with institutions and rules, in such a way as to maximise the positive outcomes of social cooperation and minimise the problems, conflicts and improper conduct.

Contemporary democracy can progress towards effective social organization when individual rights leave room for individual choices that their overall outcome forms the collective choice through the mechanism of the market in a regime of freedom underwritten by a system of legal rules. In those specific and necessary issues where a collective decision is required for the proper functioning of social organization, the state can act in partnership with the voting mechanism within a framework of strict limitations imposed by individuals with high-level constitutional backing.

The constitution in this case plays a decisive role in ensuring that its manner of drafting and the high principles of its elaboration place effective limitations on the state, not allowing the constitution to be used as a legislative point of departure for the further expansion of the state.

\section{References}

Arrow, K. (1951). Social Choice and Individual Values. New York: John Wiley \& Sons.

Baumol, W. (1952). Review of Social Choice and Individual Values. Econometrica, XX, 110. http://dx.doi.org/10.2307/1907815

Buchanan, J. M. (1954a). Individual Choice in Voting and the Market. The Journal of Political Economy, 62(4), 334-343. http://dx.doi.org/10.1086/257538

Buchanan, J. M. (1954b). Social Choice, Democracy, and Free Markets. The Journal of Political Economy, 62(2), 114-123. http://dx.doi.org/10.1086/257496

Buchanan, J. M. (1973). The Coase Theorem and the Theory of the State. Natural Resources Journal, 13, 579-594.

Buchanan, J. M. (1987). Economics, Between Predictive Science and Moral Philosophy. Texas A\&M University Press.

Coase, R. H. (1960). The Problem of Social Cost. Journal of Law and Economics, 3, 1-44. http://dx.doi.org/10.1086/466560

Coase, R. H. (1988). The Firm, the Market, and the Law. The University of Chicago Press.

Cooter, R. (1982). The Cost of Coase. Journal of Legal Studies, 11, 1-34. http://dx.doi.org/10.1086/467690

Furubotn, E. G., \& Pejovich, S. (1974). The Economics of Property Rights. Ballinger Publishing Company. 
Little, I. M. D. (1952). Social Choice and Individual Values. Journal of Political Economy, LX, 422-432. http://dx.doi.org/10.1086/257276

Rothenberg, J. (1953). Conditions for a Social Welfare Function. Journal of Political Economy, LXI, 389-405. http://dx.doi.org/10.1086/257413

\section{Notes}

Note 1. James Buchanan was the first to turn the attention of political economy to analysis of the contribution of the market mechanism to the making of decisions determining social choice, distinguishing it from the political process which in a democracy is based on the rule of the majority. The two first articles of James Buchanan which opened this field of enquiry are "Social Choice, Democracy, and Free Markets", The Journal of Political Economy, Vol. 62, No. 2 (Apr., 1954), 114-123 and "Individual Choice in Voting and the Market", The Journal of Political Economy, Vol. 62, No.4 (Aug., 1954), 334-343.

Note 2. This theorem was developed by Kenneth Arrow in his essay "Social Choice and Individual Values", New York: John Wiley \& Sons, 1951.

Note 3. Op. cit. in the Arrow essay p. 59.

Note 4. For a discussion of the Arrow theorem in a context of broader philosophical interest in its implications, see the articles of I.M.D. Little "Social Choice and Individual Values", Journal of Political Economy, LX (1952), 422-432 and Jerome Rothenberg "Conditions for a Social Welfare Function", Journal of Political Economy, LXI (1953), 389-405.

Note 5. Arrow's conditions, briefly, are 1) that the social well-being function not be imposed 2) that no person in society be able to behave as, or become, a dictator 3) If an individual prefers one social choice to another and any other individual is indifferent towards both of them, then that social choice will not be assigned a lower ranking in the social order and 4) Mutually unrelated social choices will not influence the ranking of the relevant social choices. For a more precise and stricter formulation of Arrow's conditions see the critique by William Baumol in Econometrica, XX(1952), 110.

Note 6. James Buchanan carries out a careful examination of the transaction cost approach of Ronald Coase and the economists of Property Rights in chapter 10: "Rights, Efficiency, and Exchange: The Irrelevance of Transaction Cost" of his book "Economics. Between Predictive Science and Moral Philosophy", Texas A\&M University Press, 1987 and in his article "The Coase Theorem and the Theory of the State", Natural Resources Journal 13 (October 1973), 579-594. In the former he reconstructs Coase's theorem on the basis of the contractarian line of analysis with a view to countering the trenchant critique put forward by Robert Cooter in his "The Cost of Coase", Journal of Legal Studies, 11 (January 1982), pp. 1-34. In the latter he uses Coase's theorem to highlight the ineffectiveness of state intervention. For Coase's Theorem see Ronald H. Coase "The Problem of Social Cost", Journal of Law and Economics, 3 (October 1960), pp. 1-44. For the economists of Property Rights Furubotn, Eirik G. and Pejovich, Svetozar (Eds.), "The Economics of Property Rights", Ballinger Publishing Company 1974.

\section{Copyrights}

Copyright for this article is retained by the author(s), with first publication rights granted to the journal.

This is an open-access article distributed under the terms and conditions of the Creative Commons Attribution license (http://creativecommons.org/licenses/by/3.0/). 